\title{
Duration of untreated psychosis as predictor of long-term outcome in schizophrenia: systematic review and meta-analysis ${ }^{\dagger}$
}

Matti Penttilä, Erika Jääskeläinen, Noora Hirvonen, Matti Isohanni and Jouko Miettunen

\section{Background}

Duration of untreated psychosis (DUP) is one of the few potentially modifiable predictors of outcomes of schizophrenia. Long DUP as a predictor of poor short-term outcome has been addressed in previous meta-analyses, but the long-term effects of DUP remain unclear.

\section{Aims}

To analyse the associations between DUP and long-term outcomes of schizophrenia.

\section{Method}

A systematic literature search was performed using seven electronic databases and manual searches. Random effects weighted meta-analysis with correlation coefficients was used to pool the results.

\section{Results}

We identified 3493 unique publications, from which 33 samples met our predefined selection criteria. Long DUP correlated statistically significantly with poor general symptomatic outcome, more severe positive and negative symptoms, lesser likelihood of remission and poor social functioning and global outcome (correlations 0.13-0.18). Long DUP was not associated with employment, quality of life or hospital treatment.

\section{Conclusions}

The small but mostly consistent correlation between long DUP and poor outcome indicates that early intervention in psychosis may have at least subtle positive effects on the long-term course of illness.

\section{Declaration of interest}

None.
Recent meta-analysis has shown that only $13.5 \%$ of patients with schizophrenia achieve recovery and outcome has not improved over the years. ${ }^{1}$ Despite active research, not many potentially modifiable predictors of outcomes have been identified. The duration of untreated psychosis (DUP) has been one of the most commonly studied predictors of the outcome of schizophrenia. ${ }^{2,3}$ The correlation between long DUP and poor outcome in the first years of illness has been systematically shown. ${ }^{2,3}$ The evidence for sustainable improvements in outcome by shortening DUP is inconclusive and methodically challenging. Follow-up studies of at least 5 years have shown that the beneficial effects of early intervention may not persist in the long term. ${ }^{4,5}$ In one study with a follow-up of 10 years, early detection of psychosis was associated with higher recovery rates and employment but also with higher levels of excitative symptoms. ${ }^{6}$ The long-term consequences of prolonged untreated psychosis are unclear, ${ }^{7-9}$ with no previous systematic meta-analysis with a wide perspective of outcomes focusing also on the length of follow-up. Our aim was to analyse the associations between length of DUP and long-term outcomes of schizophrenia. Our hypothesis was that long DUP associates with poor long-term clinical and social outcomes. In addition, we aimed to explore the effects of the proportion of male participants, the age at illness onset, the length of DUP, proportion of cases of schizophrenia, withdrawal percentage, length of follow-up and income level of the country on correlation between DUP and outcome.

\section{Method}

We applied the Meta-analysis of Observational Studies in Epidemiology (MOOSE) guidelines for systematic reviews and

TPreliminary results of this meta-analysis were presented at the 21st European Congress of Psychiatry, Nice, France, 2013, and the 4th European Conference on Schizophrenia Research, Berlin, Germany, 2013. meta-analyses of observational studies. ${ }^{10}$ With the help of an information scientist (N.H.) relevant literature was searched from Scopus, PubMed, Science Direct, ISI Web of Knowledge, PsycINFO (Ovid), CINAHL (EBSCO) and Academic Search Premier (EBSCO) databases in May 2013, using the following search strategy: ("duration of untreated psychosis" OR "delay in treatment" OR "treatment delay" OR "initiation of treatment" OR "duration of untreated illness") AND (psychosis OR "psychotic disorders" OR schizophrenia OR schizoaffective OR schizophreniform) (online Appendix DS1). No language, publication date or publication status restriction was imposed and the search was directed to all fields. Non-English articles were translated if necessary. Articles found through citations, reviews and meta-analyses were included in our meta-analysis. ${ }^{1}$ Authors of included samples were contacted for unpublished data. All abstracts were analysed by one author (M.P.). The excluded abstracts were then reviewed by another author (E.J.) and problematic cases were assessed by three authors (M.P., E.J. and J.M.). For studies that met inclusion criteria, a second investigator (E.J. or J.M.) checked the data accuracy. When a disagreement occurred related to data extraction, this was resolved by consensus. In keeping with related systematic reviews of schizophrenia epidemiology, ${ }^{1,11}$ we evaluated the quality and characteristics of the included studies (online Appendix DS2). Information on the data collected from the included studies is presented in online Table DS1.

\section{Study selection}

The articles included in the analyses were required to meet the following criteria:

(a) the sample included at least $50 \%$ of individuals with schizophrenia and at least $75 \%$ of individuals were diagnosed with schizophrenia, schizophreniform, schizoaffective or delusional disorder (i.e. broadly defined schizophrenia); 
(b) structured diagnostic system criteria were used;

(c) the sample size was 20 or more;

(d) the study assessed the association between DUP and at least one of clinical or social outcomes (defined later) or quality of life with minimum length of follow-up of 2 years;

(e) the definition of DUP was clear and comparable with other studies (the definition used was time between the onset of first-episode psychosis and first treatment, specifically antipsychotic medication, psychosocial treatment, contact with treatment services or first hospital admission after the onset of psychosis).

Prospective, cross-sectional and retrospective study designs were included, including register-based studies and observational clinical samples. Randomised controlled trials were excluded because of their specific inclusion criteria which limit the representativeness of these samples. Where several papers were available on the same or overlapping cohorts, we selected the results from the studies that had longest follow-up when there was no major difference in withdrawal rate. If a study had less than the required percentage of participants with schizophrenia but the results for this subgroup were presented, the subgroup results were included. Authors of excluded studies were contacted for unpublished data if inclusion was considered possible. Details of the excluded studies are available from the authors on request, and some examples are presented in online Appendix DS3. Online Appendix DS4 lists the references for the included studies.

\section{Outcome}

Outcome was categorised into nine groups: general symptomatic outcome, positive symptoms, negative symptoms, clinical remission, social functioning, employment, global outcome, quality of life and hospital treatment. The outcome categories were chosen to describe different dimensions of the outcome in schizophrenia. ${ }^{12,13}$ Factors such as suicidality, insight, excitement and depression were not included in the meta-analysis as they were reported in only a few studies. ${ }^{7,14,15}$ General symptomatic outcome describes all of the symptoms, for example as total symptoms, unspecified symptomatic remission or recovery, or score on the Clinical Global Impression (CGI) scale. Specific symptom dimensions analysed in the meta-analysis were positive and negative symptoms (Table DS1). We studied clinical remission separately using the definition of Andreasen et al, ${ }^{16}$ which is a structured, widely used and accepted definition of remission in schizophrenia. Other measurements of relapse or recovery were included in the general symptomatic outcome category. Nowadays, recovery in schizophrenia is commonly defined as remission of symptoms and improvement of social functioning. ${ }^{17}$ When the definition of recovery was not clearly described in the original studies, we assumed that recovery indicated diminished symptoms. ${ }^{1,17}$

Hospital treatments were defined as the estimated number of hospital admissions and/or days in hospital to describe the utilisation of psychiatric services, in contrast to general symptomatic outcome. Hospital admission may be a proxy measure of severity of illness, for example relapse, but other factors (related to the patient, healthcare staff, method of treatment, organisation and family) may also account for its use. Social functioning was included when studies reported occupational and social functioning using measures such as the Social and Occupational Functioning Assessment Scale (SOFAS). Specific definitions of social functioning and social activities such as hobbies and social support were also included. Employment was included when the level of work or education or the receipt of disability pension was recorded, using information from registers, interviews or questionnaires. This category describes the actual work or study that can be measured as days or percentage of time. The assessed employment and disability pension can be affected by ability of work, general employment in society and level of social security.

Global outcome included combinations of outcome variables estimating both clinical and social aspects or a single global outcome measure such as the Global Assessment of Functioning (GAF) scale. Quality of life was included from studies that had estimated the correlation between DUP and various quality of life scales. This category was created to describe participants' subjective assessment of satisfaction.

\section{Statistical analysis}

Based on the expected heterogeneity of the associations between DUP and outcomes, we used random effects models to pool overall estimates of effect sizes. In the random effects analysis each study was weighted by the inverse of its variance and the between-studies variance. Results from unadjusted analyses were included if they were given in the original studies. The effect of DUP was estimated using correlation coefficients with 95\% confidence intervals. If original studies presented other effect measures these were transformed to correlations using formulas presented by Rosenthal and colleagues. ${ }^{18,19}$ If the studies presented more than one effect measure for the same outcome group in the same sample, the average of these correlations was used in the meta-analysis. Correlation coefficients can be interpreted as effect sizes that are small $(0.10)$, moderate $(0.30)$ or large $(0.50) .{ }^{20}$ In our study negative correlation indicates that long DUP associates with poorer outcome, for example more severe symptoms and decreased functionality.

We studied the heterogeneity of the studies (i.e. how much the studies were assessing the same effect size) using the $I^{2}$ statistic. The statistical significance in heterogeneity was tested using the chi-squared test. ${ }^{21}$ Values of $I^{2}$ range from $0 \%$ to $100 \%$, reflecting the proportion of the total variation across studies beyond chance: $25 \%$ is low, $50 \%$ moderate and $75 \%$ high heterogeneity or major excessive variation across studies. ${ }^{22}$ In additional analyses we used meta-regression to estimate the effect of possible confounders on the correlations in different outcome groups. ${ }^{23}$ Included potential confounders were gender distribution (proportion of male participants), mean age at onset, mean length of DUP, proportion of participants diagnosed with schizophrenia, percentage withdrawing, study design, mean follow-up length and income level of the country (economic index of the country based on per capita income World Bank statistics for 1988; data.worldbank.org): lowincome (US\$1005 or less), lower-middle income (\$1006-3975), upper-middle income (\$3976-12 275) and high-income economies (\$12 276 or more).

We also made an influence analysis in which the meta-analysis estimates were computed omitting one study at a time. Possible publication bias was studied using the Begg's test for small-study effects. ${ }^{23}$ An alpha level of 0.05 was used for all statistical tests. Stata version 11 for Windows ${ }^{21}$ was used in all analyses.

\section{Results}

The search produced 4495 results and, after the removal of duplicates, 3493 publications were identified. Based on the information on abstracts, 193 articles were selected for comprehensive evaluation and 56 articles were found from other sources, leading to a total of 249 articles that were evaluated. Thirty-nine articles analysing 33 different samples met our inclusion criteria and were included in the meta-analysis (Fig. 1). 
Main reasons for exclusion were that the study did not analyse DUP (52 studies) or its association with long-term outcome (53 studies), or the outcome studied did not meet the inclusion criteria (e.g. cognition: 50 studies).

\section{Study characteristics and quality}

Table DS1 reports the main characteristics of studies included in the meta-analysis. In these studies mean age at onset was 24.4 years (range 12.2-31.5), mean length of follow-up was 8.1 years (range 2-28), mean length of DUP was 61.3 weeks (range 10.4213.2) and, on average, 50.5\% (range 29.8-77.3) of the samples were male. Withdrawal percentages were $4-71 \%$, and exceeded $50 \%$ in five samples; for two studies information on number of participants leaving the study was not available. Included studies did not use any statistical method to take attrition into account in analyses. Sample sizes at the end of the follow-up period varied between 23 and 776. Study populations were mostly clinical samples drawn from people with first-episode psychosis from both out-patient and in-patient care; 13 samples were drawn from one type of care only. This information was not available for two samples. Diagnoses were classified mainly based on DSM-III-R (5 studies), DSM-IV (18 studies), ICD-9 (4 studies) and ICD-10 (4 studies). The percentage of participants with a diagnosis of schizophrenia was $60-100 \%$. Duration of psychosis was mostly defined using interviews; the method used for its definition was not reported for 10 samples. Outcomes were most frequently defined using validated scales, but in some studies the scale or its use were not clearly reported. Interrater reliability was rarely estimated for the definition of DUP or outcomes (Table DS2).

The number of studies in different outcome categories varied from 7 to 19. The correlations between length of DUP and outcomes of original studies are presented in Table DS3. The majority of correlations were unadjusted, with only one study having only adjusted correlations available. ${ }^{24}$ Three studies presented one of the several correlations between DUP and outcome only as adjusted. ${ }^{25-27}$ Details of the results and which of them were transformed into correlations, as well as the covariates used in the original studies, are outlined in Table DS3. When the analyses presented below were done with only unadjusted correlations, the results did not change.

\section{Association between DUP and outcome categories}

General symptomatic outcome and its correlation with DUP were available for 15 samples; DUP and both positive and negative symptoms were studied in 18 samples, and remission and its correlation with DUP were obtained from 10 samples. Long DUP associated with more severe outcome in all these categories (general symptomatic outcome: $r=-0.15,95 \%$ CI -0.22 to -0.09 ; positive symptoms: $r=-0.14,95 \%$ CI -0.22 to -0.07 ; negative symptoms: $r=-0.13,95 \% \mathrm{CI}-0.21$ to -0.05 ; remission: $r=-0.14,95 \%$ CI -0.23 to -0.06$)$. The estimated correlation between DUP and hospital treatment from 11 samples was small and not statistically significant $(r=-0.09,95 \% \mathrm{CI}-0.22$ to 0.04). Long DUP correlated with poor social functioning (14 samples, $r=-0.18,95 \%$ CI -0.27 to -0.09$)$. There was no correlation between DUP and employment $(7$ samples, $r=-0.05,95 \%$ CI -0.16 to 0.06$)$. Long DUP correlated with poor global outcome (19 samples, $r=-0.17,95 \%$ CI -0.26 to -0.07). A small but statistically non-significant correlation between DUP and quality of life was found $(7$ samples, $r=-0.10,95 \%$ CI -0.22 to 0.01 ). Forest plots including correlations (with 95\% CIs) in individual studies in the different outcome categories are presented in online Figs DS1-DS9. The

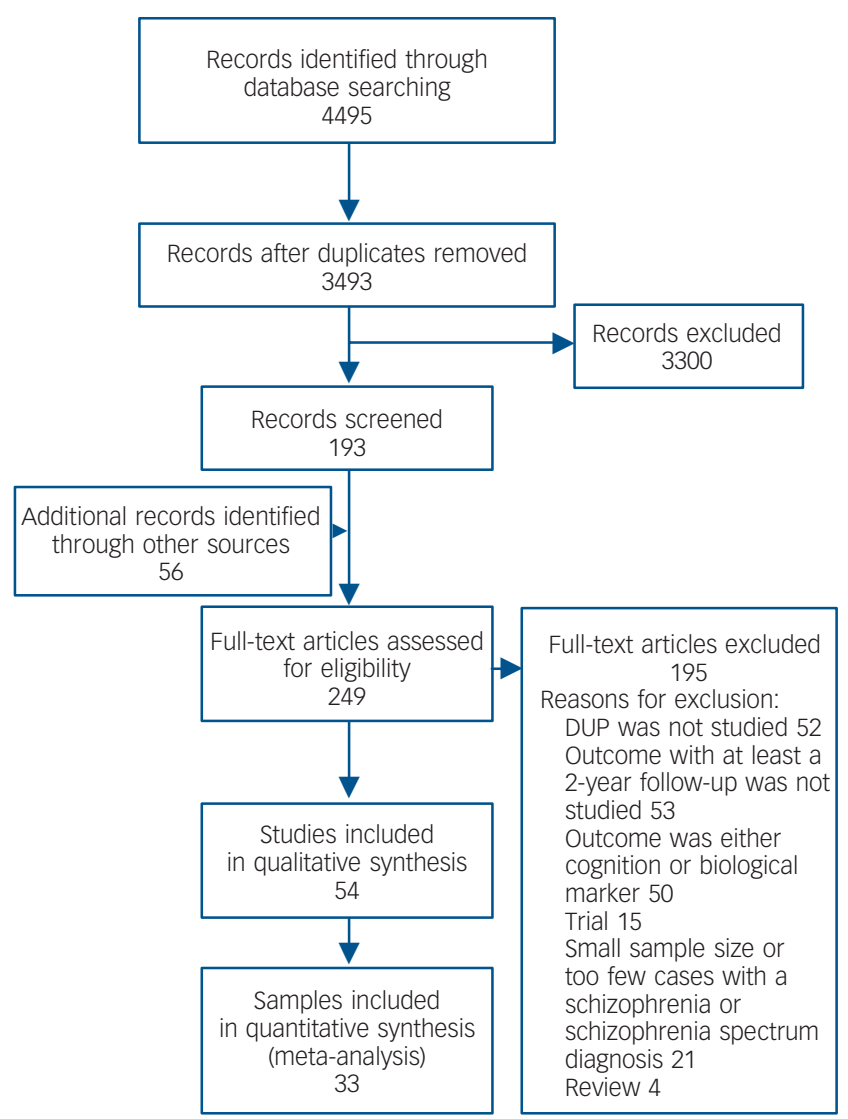

Fig. 1 Literature search and selection of the studies (adapted

from the PRISMA flowchart, www.prisma-statement.org

DUP, duration of untreated psychosis.

overall correlations in different outcome categories are summarised in Fig. 2.

\section{Heterogeneity}

Categories of positive symptoms $\left(I^{2}=56.1 \%, P=0.002\right)$, negative symptoms $\left(I^{2}=66.1 \%, P<0.001\right)$ and remission $\left(I^{2}=54.7 \%\right.$, $P=0.019)$ as well as general symptomatic outcome were statistically significantly and moderately heterogeneous $\left(I^{2}=38.9 \%, P=0.061\right)$.

Outcomes Correlation $(95 \% \mathrm{Cl})$

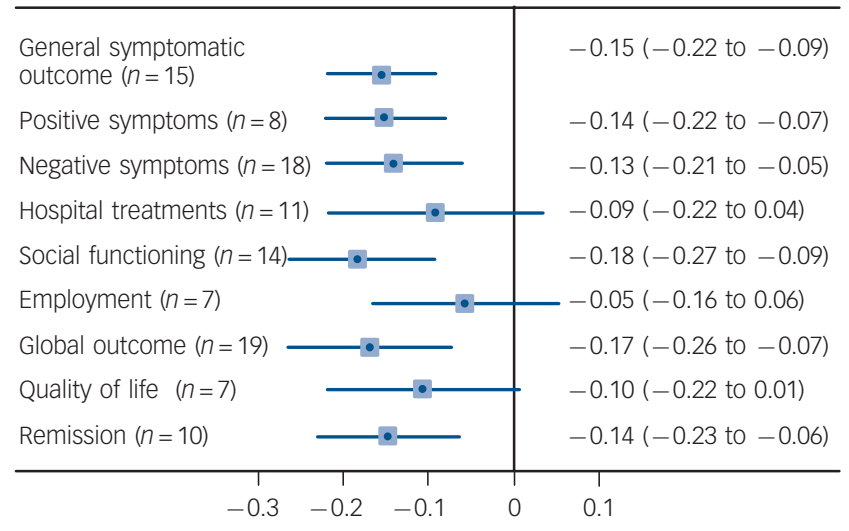

Fig. 2 Correlations between duration of untreated psychosis (DUP) and clinical outcomes, hospital treatment and social functioning. Negative correlation indicates that long DUP is associated with poor outcome ( $n$, number of studies). 
There was high and significant heterogeneity between studies of DUP and hospital treatment $\left(I^{2}=75.8 \%, P<0.001\right)$. Studies of social functioning $\left(I^{2}=68.2 \%, \quad P<0.001\right), \quad$ employment $\left(I^{2}=55.1 \%, P=0.038\right)$, global outcome $\left(I^{2}=73.8 \%, P<0.001\right)$ and quality of life $\left(I^{2}=55.0 \%, P=0.038\right)$ were all moderately heterogeneous.

\section{Covariates in meta-regression}

In additional analyses several study characteristics were used as potential confounders in meta-regression. Gender distribution, onset age, length of DUP, the proportion of participants with schizophrenia, withdrawal percentage and study design did not affect the correlation between DUP and outcomes. Longer follow-up resulted in stronger associations between DUP and negative symptoms $(P=0.035)$, hospital treatment $(P=0.046)$ and global outcome $(P=0.035)$. Higher national income level resulted in stronger correlation between DUP and general symptomatic outcome $(P=0.008)$ and positive symptoms $(P=0.016)$ (online Table DS4).

\section{Influence analysis and publication bias}

In the influence study correlations were not affected statistically significantly when one study was excluded at a time. In the analyses of publication bias, statistically significant bias was not found in Begg's test for small-study effects.

\section{Discussion}

We found a significant association between long DUP and poor general symptomatic outcome, more severe positive and negative symptoms and failure to achieve remission, as well as decreased social functioning and global outcome. There was no significant correlation between DUP and employment, quality of life or hospital treatment. Few of the correlations tended to be stronger in studies with longer follow-up and in countries with higher level of income. The relatively high withdrawal rate in the original studies and variation in the methods of defining DUP and outcomes increased the risk of selection and information bias.

\section{Comparison with earlier studies}

Previous systematic reviews and meta-analyses of DUP and outcome of schizophrenia have mainly focused on the short-term outcome. The general conclusion of previous reviews was that short DUP seemed to be related to better outcome, whereas long DUP was related to poorer clinical and functional outcome and quality of life. ${ }^{2,3}$ The small correlations between long DUP and poor clinical outcome are similar to earlier meta-analyses., ${ }^{2,3}$ Boonstra et al found that over an 8-year follow-up period the correlation between long DUP and negative symptoms increased from $r=0.12$ at baseline to $r=0.20,{ }^{28}$ which is in line with our finding that the correlation between DUP and negative symptoms was stronger when follow-up was longer. The correlations between DUP and remission (as defined by Andreasen et $\mathrm{al}^{16}$ ) and hospital treatment have not previously been subjected to meta-analysis. The correlation between long DUP and a decline in social functioning seems to be small, but significant also in the long term. We were the first to study DUP and employment in meta-analysis, and found no significant association.

In meta-regression the length of follow-up had a statistically significant effect on the correlation between DUP and negative symptoms, hospital treatment and global outcome. Interestingly, the correlation between long DUP and poor outcome was stronger in longer follow-up periods. This does not prove that long DUP causes poor outcome, ${ }^{29}$ but may indicate that participants with longer DUP have a different type of illness or different coping mechanisms for the symptoms, as well as different cognitive performance from some participants with short DUP. For example, it is possible that more severe negative symptoms, as part of an insidious mode of onset, are one reason for longer DUP, ${ }^{30,31}$ and this type of disorder relates to poor prognosis. This association could remain during the course of illness. It is debatable whether shortening the DUP would decrease negative symptoms, as current treatment options do not generally greatly improve the outcome of such symptoms. ${ }^{32}$

A previous review suggested that the correlation between DUP and outcome in developing countries was somewhat contradictory as the DUP tended to be longer but remission rates were higher, despite some correlation between long DUP and poor outcome. ${ }^{33}$ Our meta-analysis gives only limited information on differences between countries based on the level of income. There was no study from a low-income country and only a few (from none to four) studies from countries with lower- or higher-middle level of income in each of the outcome categories. However, the correlations between DUP and general symptomatic outcome and positive symptoms seemed to be smaller in countries with a lower income level.

\section{Methodological discussion and risk of bias}

Varying degrees of heterogeneity were found between studies in different outcome categories. This possibly reflects the heterogeneity of DUP and the measures of outcome used. The heterogeneity between studies indicates methodological differences and differences in clinical protocols between countries' treatment units. Both of these could affect not only the estimation of DUP and outcomes, but may also have confounding effects on both of them. The definition of DUP is challenging and the comparison between participants and samples based on the length of DUP is not always exact. The reasons behind the prolonged periods of untreated psychosis may vary. It might be due to poor insight and more severe types of disorder, but equally in some individuals it could reflect good coping abilities and levels of support, allowing people with psychotic symptoms to live without resorting to mental healthcare and without an accurate diagnosis. The characteristics of local health services may also affect the length of DUP. ${ }^{32}$

Defining DUP in a standardised fashion could be one way to decrease variability between studies. The use of a proposed definition of DUP, which takes into account not only the duration of symptoms but also their severity, could be a more accurate means of measuring the potential harmful effects of DUP and reducing the levels of heterogeneity found in our study. ${ }^{31}$ Unfortunately detailed assessment of DUP in many of the included studies was not possible owing to limited information given on the methods of defining DUP and their reliability. A number of studies did use structured interviews with more than one source of information, which can be considered reliable, and studies that did not clearly define and separate DUP from (for example) duration of untreated illness were excluded.

Different aspects of possible bias need to be considered. Selection bias may have been present in the original studies as participants with better or worse outcomes might have been left out during the several years of follow-up, and perhaps more probably patients with long DUP might have been more difficult to engage during the study. Some of these issues could be minimised in future studies with more synchronised study designs and systematic measurements of exposure and outcome. In 
observational designs, investigations are at risk of confounding. The DUP most probably affects treatment in a way that might confound the association between DUP and outcomes. Some confounders, such as personal characteristics of temperament, may affect both DUP and treatment adherence. ${ }^{9}$ Mode of onset is another possible confounding factor. ${ }^{34}$ However, this was taken into account in four of the original samples without significant effect on the correlation between DUP and outcome. ${ }^{7,35-37}$ Norman et al found no significant correlation between DUP and mode of onset and found significant correlation with outcome and both of them in only two of eight outcome variables, ${ }^{38}$ whereas Selten et al found significant association $(P<0.001)$ between mode of onset and poor outcome, but no clear association with DUP and poor outcome $(P=0.08) .{ }^{39}$ However, in forthcoming studies mode of onset or other markers of severity of the early phase of illness should be taken into account.

Owing to the methodological variation between original studies we were unable to analyse systematically the effect of all possible confounders, but using meta-regression variables such as gender and age at onset seemed to have no major confounding effect. The method of meta-regression used is not the most efficient way to study possible confounders, but as original studies rarely studied confounders, this was our only option. Additionally, the possibility of multiple testing and low number of studies in some of the outcome categories should be noted. Therefore, the possible confounding bias should be considered when interpreting the results of this meta-analysis.

Another methodological challenge was the possible correlation between different outcome categories. Owing to our definition of general symptomatic outcome, results from PANSS scores could have been included in both general symptomatic outcome and positive and negative symptoms. This should also be considered when interpreting the results. As the original studies did not study the correlations between different outcomes, it was not possible to analyse the effect of these correlations in our meta-analysis.

Positive study findings are more likely to be reported than negative findings, which may bias the results of meta-analysis of observational studies. The negative finding regarding publication bias needs to be assessed with caution because the method used (Begg's test) is not very powerful in detecting bias with a small number of included studies. The observed heterogeneity between studies also presents a challenge in synthesising their results. Our approach, using random effects models, can be considered reliable for studying this sort of data. Sample sizes of included studies varied from 23 to 776, with the majority of studies having relatively small samples. Most of the studies had quite high rates of withdrawal during the follow-up period, which increases the risk of selection bias. The possibility of outcome reporting bias was reduced by contacting authors for their unpublished results and data.

\section{Strengths and limitations}

The literature search for the meta-analysis was done using several databases. Articles published in languages other than English were included and were translated by professionals. We also used criteria requiring the majority of participants to have been diagnosed with schizophrenia and at least three out of four with schizophrenia spectrum disorder, which is somewhat stricter than the criteria used in previous meta-analyses. ${ }^{3}$ Some studies with remarkably different definitions of DUP were excluded from the meta-analysis. ${ }^{31}$ We were not able to include some of the earliest studies of delayed treatment and long-term outcome in schizophrenia, ${ }^{34-36}$ owing to variations in definitions of diagnosis and
DUP. Most of the studies published before the 1990s defined DUP as the duration of symptoms prior to treatment and no information was provided as to whether these symptoms were positive or negative and what threshold was defined for their onset. ${ }^{40,41}$ The end of DUP had also been defined as the beginning of antipsychotic treatment in one sample, in which participants had their first episode of psychosis in the pre-antipsychotics era, leading to DUPs of over 10 years. ${ }^{42}$ However, the results of these studies were similar to our findings: Rupp \& Fletcher found that duration of symptoms (especially if more than 2 years) before treatment decreased the probability of the improvement of outcome, ${ }^{40}$ and Scully et al concluded that more severe negative symptoms were predicted by longer DUP. ${ }^{42}$ The exclusion of randomised controlled trials, most notably the OPUS trial, should not cause an underestimation of the correlation between DUP and outcome in this meta-analysis. ${ }^{43,44}$

There are limitations in this study's design. Possible differences in the original samples may have affected our results and conclusions. There were only 7 to 19 samples in the different outcome categories. The studies also differed largely in terms of the research methods used. As the original studies presented their results with various effect size measures, we were forced to convert them to correlations using previously presented equations. ${ }^{18,19}$ These conversions can create inaccuracy, as the equations for the conversions are based on normal distribution. ${ }^{18,19}$ However, the use of random weights is an advantage and reduces the risk of such inaccuracies. Most of the studies had analysed the association between DUP and symptoms or global outcome. Owing to the small number of studies definitive conclusions should not be made regarding the longitudinal effects of DUP on, for example, employment and quality of life.

\section{Implications}

When developing new treatments for schizophrenia it is important to have a broad knowledge of the effects of current treatment options and periods when the illness has not been treated. Possible differences in the lifestyles of patients with long DUP, compared with those with short DUP, could provide new information for use in the treatment of schizophrenia. It has previously been shown that more severe negative and depressive symptoms correlated with decreased quality of life in schizophrenia, ${ }^{45}$ and early intervention might not be able to improve the quality of life in this disorder. ${ }^{46}$ Therefore, the factors behind our finding that people with long DUP might have as good a quality of life as those with shorter DUP should be studied further. Future studies of DUP and outcome should use more standardised methods for defining both DUP and outcomes. It would also help the generalisation of results in clinical practice if potential confounders were approached more systematically in studies.

The small correlation between long DUP and poor long-term outcome indicates that early intervention and care in psychosis might have some positive effects on the long-term outcome on schizophrenia. However, drawing evidence-based clinical conclusions from analyses using natural experiments and observational designs is problematic as it is neither possible nor ethical to randomise people to different conditions regarding DUP. It is likely that in the long term other factors (such as individual characteristics, social support and treatment factors) are more influential than DUP in determining outcomes. However, the constant, subtle correlation between long DUP and poor outcome dictates that periods of untreated psychosis should be shortened whenever possible. 
Matti Penttilä, MD, PhD, University of Oulu, Institute of Clinical Medicine Department of Psychiatry, and Oulu University Hospital, Oulu; Erika Jääskeläinen $\mathrm{MD}, \mathrm{PhD}$, University of Oulu, Institute of Clinical Medicine, Department of Psychiatry, and Institute of Health Sciences, and Oulu University Hospital, and Medical Research Center Oulu; Noora Hirvonen, MSc, University of Oulu, Institute of Clinical Medicine, Center Oulu; Noora Hirvonen, MSc, University of Oulu, Institute of Clinical Medicin,
Department of Psychiatry, and Faculty of Humanities, Information Studies, Oulu; Department of Psychiatry, and Faculty of Humanities, Information Studies, Oulu;
Matti Isohanni, MD, PhD, University of Oulu, Institute of Clinical Medicine, Department of Psychiatry, and Oulu University Hospital, Oulu; Jouko Miettunen PhD, University of Oulu, Institute of Clinical Medicine, Department of Psychiatry, and Institute of Health Sciences, and Oulu University Hospital, and Medical Research Center Oulu, Finland

Correspondence: Matti Penttilä, University of Oulu, PO Box 5000, Oulu 90014, Finland. Email: matti.penttila@oulu.fi

First received 11 Feb 2013, final revision 27 Feb 2014, accepted 14 Mar 2014

\section{Funding}

This work was supported by Oulu University Hospital, University of Oulu, the Academy of Finland; the Sigrid Jusélius Foundation; National Alliance for Research in Schizophrenia and Affective Disorders (NARSAD): The Brain and Behavior Research Fund (Dr Mortimer and Affective Disorders (NARSAD): The Brain and Behavior Research Fund (Dr Mortimer
D. Sackler Developmental Psychobiology Research Program); the Oulu University Pharmacy Foundation; H. Lundbeck; the Northern Finland Health Care Support Foundation; and the Jalmari and Rauha Ahokas Foundation.

\section{Acknowledgements}

We thank Dr David Cowling for proofreading the manuscript. We acknowledge the contribution of all contacted authors who responded and especially Drs Robert Boden, Svein Friis, Ingrid Melle and Ghada Hassan for providing unpublished results or data for the analyses in this meta-analysis.

\section{References}

1 Jääskeläinen E, Juola P, Hirvonen N, McGrath JJ, Saha S, Isohanni M, et al. A systematic review and meta-analysis of recovery in schizophrenia. Schizophr Bull 2013; 39: 1296-306.

2 Marshall M, Lewis S, Lockwood A, Drake R, Jones $\mathrm{P}$, Croudace $\mathrm{T}$. Association between duration of untreated psychosis and outcome in cohorts of first-episode patients: a systematic review. Arch Gen Psychiatry 2005; 62: 975-83.

3 Perkins DO, Gu H, Boteva K, Lieberman JA. Relationship between duration of untreated psychosis and outcome in first-episode schizophrenia: a critical review and meta-analysis. Am J Psychiatry 2005; 162: 1785-804.

4 Bertelsen $\mathrm{M}$, Jeppesen $\mathrm{P}$, Petersen L, Thorup A, Øhlenschlaeger J, le Quach P, et al. Five-year follow-up of a randomized multicenter trial of intensive early intervention vs standard treatment for patients with a first episode of psychotic illness: the OPUS trial. Arch Gen Psychiatry 2008; 65: 762-71.

5 Gafoor R, Nitsch D, Mccrone P, Craig TKJ, Garety PA, Power P, et al. Effect of early intervention on 5-year outcome in non-affective psychosis. Br J Psychiatry 2010; 196: 372-6.

6 Hegelstad WT, Larsen TK, Auestad B, Evensen J, Haahr U, Joa I, et al. Long-term follow-up of the TIPS early detection in psychosis study: effects on 10-year outcome. Am J Psychiatry 2012; 169: 374-80.

7 Penttilä $\mathrm{M}$, Miettunen J, Koponen $\mathrm{H}$, Kyllönen $\mathrm{M}$, Veijola J, Isohanni $\mathrm{M}$, et al. Association between the duration of untreated psychosis and short- and long-term outcome in schizophrenia within the Northern Finland 1966 Birth Cohort. Schizophr Res 2013; 143: 3-10.

8 Norman RMG, Townsend L, Malla AK. Duration of untreated psychosis and cognitive functioning in first-episode patients. Br J Psychiatry 2001; 179: $340-5$.

9 Dassa D, Boyer L, Benoit M, Bourcet S, Raymondet P, Bottai T. Factors associated with medication non-adherence in patients suffering from schizophrenia: a cross-sectional study in a universal coverage health-care system. Aust N Z J Psychiatry 2010; 44: 921-8.

10 Stroup DF, Berlin JA, Morton SC, Olkin I, Williamson GD, Rennie D, et al. Meta-analysis of observational studies in epidemiology: a proposal for reporting. Meta-analysis Of Observational Studies in Epidemiology (MOOSE) group. JAMA 2000; 283: 2008-12.

11 McGrath J, Saha S, Welham J, El Saadi O, MacCauley C, Chant D. A systematic review of the incidence of schizophrenia: the distribution of rates and the influence of sex, urbanicity, migrant status and methodology. BMC Med 2004; 28: 2-13.

12 Menezes NM, Arenovich T, Zipursky RB. A systematic review of longitudina outcome studies of first-episode psychosis. Psychol Med 2006; 36: 1349-62.
13 Shrivastava A, Johnston M, Shah N, Bureau Y. Redefining outcome measures in schizophrenia: integrating social and clinical parameters. Curr Opin Psychiatry 2010; 23: 120-6.

14 Parellada M, Boada L, Fraguas D, Reig S, Castro-Fornieles J, Moreno D, et al. Trait and state attributes of insight in first episodes of early-onset schizophrenia and other psychoses: a 2-year longitudinal study. Schizophr Bull 2011; 37: 38-51.

15 Nielssen OB, Malhi GS, McGorry PD, Large MM. Overview of violence to self and others during the first episode of psychosis. J Clin Psychiatry 2012; 73: e580-7.

16 Andreasen NC, Carpenter WT, Kane JM, Lasser RA, Marder SR, Weinberger DR. Remission in schizophrenia: proposed criteria and rationale for consensus. Am J Psychiatry 2005; 162: 441-9.

17 Faerden A, Nesvåg R, Marder SR. Definitions of the term 'recovered' in schizophrenia and other disorders. Psychopathology 2008; 41: 271-8.

18 Rosenthal R. Parametric measures of effect size. In The Handbook of Research Synthesis (eds H Cooper, LV Hedges). Sage, 1994.

19 Rosenthal R, Rosnow RL, Rubin DB. Contrasts and Effect Sizes in Behavioral Research: A Correlational Approach: 212. Cambridge University Press, 2000

20 Cohen J. A power primer. Psychol Bull 1992; 112: 155-9.

21 Stata Corporation. Stata User's Guide, Release 11. Stata Press; 2009.

22 Higgins JP, Thompson SG, Deeks JJ, Altman DG. Measuring inconsistency in meta-analyses. BMJ 2003; 327: 557-60.

23 Sterne J. Meta-Analysis in Stata: An Updated Collection from the Stata Journal. Stata Press, 2009

24 Röpcke B, Eggers C. Early-onset schizophrenia: a 15-year follow-up. Eur Child Adolesc Psychiatry 2005; 14: 341-50.

25 Górna K, Jaracz K, Rybakowski F, Rybakowski J. Determinants of objective and subjective quality of life in first-time-admission schizophrenic patients in Poland: a longitudinal study. Qual Life Res 2008; 17: 237-47.

26 White C, Stirling J, Hopkins R, Morris J, Montague L, Tantam D, et al. Predictors of 10-year outcome of first-episode psychosis. Psychol Med 2009; 39: $1447-56$.

27 Hill $M$, Crumlish N, Clarke M, Whitty $P$, Owens $E$, Renwick $L$, et al. Prospective relationship of duration of untreated psychosis to psychopathology and functional outcome over 12 years. Schizophr Res 2012; 141: 215-21.

28 Boonstra N, Klaassen R, Sytema S, Marshall M, De Haan L, Wunderink L, et al. Duration of untreated psychosis and negative symptoms - a systematic review and meta-analysis of individual patient data. Schizophr Res 2012; 142: $12-9$.

29 McGlashan TH. Premorbid adjustment, onset types, and prognostic scaling still informative? Schizophr Bull 2008; 34: 801-5.

30 compton MT, Chien VH, Leiner AS, Goulding SM, Weiss PS. Mode of onset of psychosis and family involvement in help-seeking as determinants of duration of untreated psychosis. Soc Psychiatry Psychiatr Epidemiol 2008; 43: $975-82$.

31 Compton MT, Gordon TL, Weiss PS, Walker EF. The 'doses' of initial, untreated hallucinations and delusions: a proof-of-concept study of enhanced predictors of first-episode symptomatology and functioning relative to duration of untreated psychosis. J Clin Psychiatry 2011; 72 1487-93.

32 Tandon R. Antipsychotics in the treatment of schizophrenia: an overview J Clin Psychiatry 2011; 72 (supp 1): 4-8.

33 Chiliza B, Asmal L, Emsley R. Early intervention in schizophrenia in developing countries: focus on duration of untreated psychosis and remission as a treatment goal. Int Rev Psychiatry 2012; 24: 483-8.

34 Moncrieff J. Questioning the 'neuroprotective' hypothesis: does drug treatment prevent brain damage in early psychosis or schizophrenia? Br J Psychiatry 2011; 198: 85-7.

35 Ichinose $H$, Nakane $Y$, Nakane $H$, Kinoshita $H$, Ohta $Y$, Honda $S$. Nagasaki Schizophrenia Study: relationship between ultralong-term outcome (after 28 years) and duration of untreated psychosis. Acta Med Nagasaki 2010; 54: 59-66.

36 Bottlender $\mathrm{R}$, Sato $\mathrm{T}$, Jager $\mathrm{M}$, Wegener $\mathrm{U}$, Wittmann J, Strauss $\mathrm{A}$, et al. The impact of the duration of untreated psychosis prior to first psychiatric admission on the 15-year outcome in schizophrenia. Schizophr Res 2003; 62: $37-44$.

37 Chang WC, Tang JY, Hui CL, Lam MM, Wong GH, Chan SK, et al. Duration of untreated psychosis: relationship with baseline characteristics and threeyear outcome in first-episode psychosis. Psychiatry Res 2012; 198: 360-5.

38 Norman RM, Manchanda R, Windell D, Harricharan R, Northcott S, Hassall L. The role of treatment delay in predicting 5-year outcomes in an early intervention program. Psychol Med 2012; 42: 223-33. 
39 Selten JP, Veen ND, Hoek HW, Laan W, Schols D, van der Tweel I, et al. Early course of schizophrenia in a representative Dutch incidence cohort. Schizophr Res 2007; 97: 79-87.

40 Rupp C, Fletcher E. A five to ten year follow-up study of 641 schizophrenic cases. Am J Psychiatry 1940; 96: 877-88.

41 Achte $\mathrm{K}$. On prognosis and rehabilitation in schizophrenic and paranoid psychoses: a comparative follow-up study of two series of patients first admitted to hospital in 1950 and 1960 respectively. Acta Psychiatr Scand 1967; 43: 9-217.

42 Scully PJ, Coakley G, Kinsella A, Waddington JL. Psychopathology, executive (frontal) and general cognitive impairment in relation to duration of initially untreated versus subsequently treated psychosis in chronic schizophrenia. Psychol Med 1997; 27: 1303-10.
43 Jeppesen $\mathrm{P}$, Petersen $\mathrm{L}$, Thorup A, Abel MB, Øhlenschlaeger J, Christensen TO, et al. The association between pre-morbid adjustment, duration of untreated psychosis and outcome in first-episode psychosis. Psychol Med 2008; 38: 1157-66.

44 Petersen L, Thorup A, Øqhlenschlaeger J, Christensen TØ, Jeppesen $\mathrm{P}$ Krarup G, et al. Predictors of remission and recovery in a first-episode schizophrenia spectrum disorder sample: 2-year follow-up of the OPUS trial. Can J Psychiatry 2008; 53: 660-70.

45 Tomotake M. Quality of life and its predictors in people with schizophrenia. J Med Invest 2011; 58: 167-74.

46 Thorup A, Petersen L, Jeppesen $\mathrm{P}$, Nordentoft M. The quality of life among first-episode psychotic patients in the OPUS trial. Schizophr Res 2010; 116 $27-34$.

\section{psychiatry and sacred texts}

\section{Symeon the Holy Fool: patron of the mentally ill}

\section{Fernando Espí Forcén and Carlos Espí Forcén}

Every professional guild or social group has always had a patron saint. That of the mentally ill is Symeon Salus (the fool), whose hagiography - the life of a saint - shares some symptoms of madness that gained him the patronage of this particular group. Symeon was an anchorite who was reportedly born in the city of Edessa, Syria in the 6th century AD. His life was dramatised in the 7th century as Life and conduct of Abba Symeon Called the Fool for the Sake of Christ written in Greek by Leontius of Neapolis (on Cyprus). Even if it is probably based on some biographical details narrated in the 6th-century Ecclesiastical History by Evagrius Scholasticus, the story of Symeon must be considered an original work of Leontius.

Like other ancient anchorites such as Symeon Stylite or Saint Anthony Abbot, he committed to a long period of retirement with his friend John. At a certain point Symeon Salus felt the call from God to save human souls in a very particular way: he purportedly chose to look insane and moved to the city of Emesa. Before arriving in the city, he found a dead dog in a dunghill; he loosened the rope of his tunic, tied a dog's paw with it and dragged the carcass on the floor as he was entering the gates of the city. some children nearby saw him and cried 'Hey, a crazy monk', they ran after him and boxed him on the ears. The following day, which was a Sunday, Symeon went to church and started cracking nuts noisily. After that, he

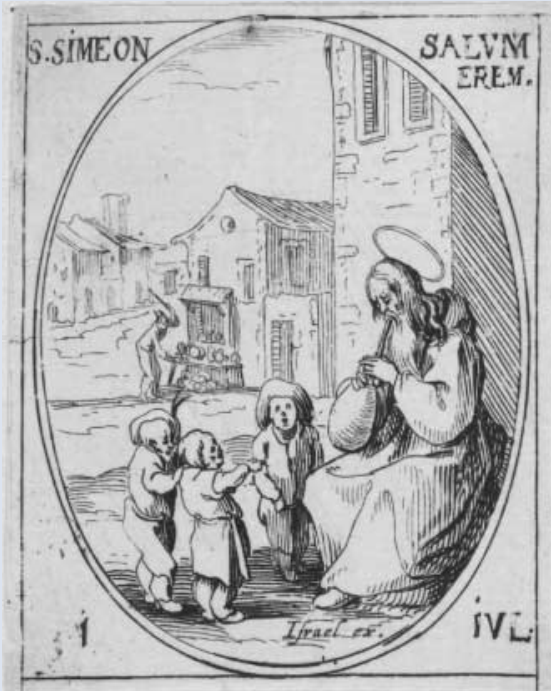

Jacques Callot, Saint Simeon Salus, 17th century. Imaging Department (c) President and Fellows of Harvard College. Reproduced with permission. snuffed the candles and when people ran after him to expel him from the church he pelted women violently with the nuts. Once he was expelled, he overturned the tables of the pastry chefs, and they consequently almost beat him to death.

The life of Symeon contains common features with traditional hagiographical literature with the purpose of showing that the saint was an imitator of Christ. Thus, Symeon gives food to the poor, practises exorcisms and saves people from sins. Nonetheless, he had erratic behaviours unparalleled in other anchorites that constantly provoked public scandals: he ate copiously in taverns, defecated in the streets, practised nudism, entered the baths of women, pretended to rape a woman and walked around being carried and whipped by prostitutes in a sadomasochistic manner. The behaviours described in the life of Symeon could be compatible with severe mental illness, but his reputation made him turn the patron of the mentally ill, whose festivity is celebrated on 1 July. Probably due to the eccentricity of Symeon Salus, there is not an iconographical tradition of him and therefore no devotional images. Calendars are probably the only visual source for Symeon Salus. A 17th-century French calendar illustrates the festivity of 1 July with a beautiful etching by the artist Jacques Callot that lyrically depicts Symeon in the city of Emesa surrounded by children. 